\title{
Developing the Intercultural Competence of Graduate Students
}

\author{
Nanda Dimitrov, Debra L. Dawson, Karyn C. Olsen, Ken N. Meadows \\ The University of Western Ontario
}

\begin{abstract}
This study explores how teaching development programs may facilitate the development of intercultural competence in graduate students and prepare them for communicating effectively in the global workplace after graduation. First, we describe the concept of intercultural teaching competence and examine the skills that graduate students may need to cultivate in order to communicate effectively in culturally diverse settings. Then, we discuss the findings of our qualitative study on the impact of teaching development programs enhanced with intercultural communication components. As a result of training, participants became more aware of cultural and disciplinary differences in communication, were able to adapt their communication style to audiences with different levels of background knowledge, and felt more prepared for interpersonal interactions across cultures with undergraduates. Finally, participants were able to transfer the skills learned to other areas of graduate study and used effective intercultural communication strategies when interacting with globally diverse peers and faculty supervisors.
\end{abstract}

\section{Résumé}

Cette étude explore la manière dont les programmes de perfectionnement pédagogique peuvent faciliter l'acquisition de compétences interculturelles chez les étudiants des cycles supérieurs et les préparer à communiquer efficacement une fois sur le marché mondial du travail, à la fin de leurs études. Nous décrivons d'abord le concept de « compétences interculturelles en milieu d'enseignement » et étudions les compétences que les étudiants aux cycles supérieurs peuvent devoir acquérir afin de communiquer efficacement s'ils enseignent dans des milieux culturellement diversifiés. 
Ensuite, nous présentons les résultats de notre étude qualitative portant sur les répercussions des programmes de perfectionnement pédagogique enrichis de composantes portant sur la communication interculturelle. Après avoir suivi cette formation, les participants ont davantage pris conscience des différences culturelles et disciplinaires en matière de communication, étaient capables d'adapter leur style de communication à des auditoires aux niveaux de connaissance variés et se sont sentis mieux préparés aux interactions interpersonnelles avec des étudiants de premier cycle provenant de divers milieux culturels. Pour finir, les participants ont été en mesure de transférer les compétences apprises à d'autres domaines de leurs études supérieures et d'utiliser effectivement des stratégies de communication interculturelle dans leurs rapports avec leurs pairs et avec leurs supérieurs universitaires issus de milieux divers.

\section{Introduction}

The research landscape and world of employment that graduate students enter after completing their degrees at Canadian universities is increasingly international and culturally diverse, involving collaboration with colleagues from around the world (Adler, 2008; Knight \& Madden, 2010). In these globally connected work settings, new researchers and professionals need to demonstrate intercultural competence in order to succeed (Deardorff, 2006). In academic settings, intercultural competence may include the ability to present research or facilitate learning across cultures, speak with confidence to a variety of audiences, explain complex concepts clearly, and negotiate working relationships across cultural, social, professional, and disciplinary boundaries (Gilbert, Balatti, Turner, \& Whitehouse, 2004; Spitzberg \& Chagnon, 2009). For example, graduates may be expected to participate in international research teams in which some group members may give feedback very directly while others prefer to communicate indirectly through implication. Graduates may also contribute to interdisciplinary dialogue and explain their research to colleagues who are unfamiliar with specialized technical discourse (Benninghoff \& Sormani, 2008; Dimitrov, 2012). Further, they may be expected to navigate power structures and relationships in multinational organizations or multicultural communities respectfully and effectively (King \& Baxter-Magolda 2005; Steers, Nardon, \& Sanchez-Runde, 2013).

While intercultural competence and "global awareness" (Green, 2012) are important outcomes of university education, they are rarely taught explicitly, and it is often assumed that students will acquire them through experience. "Culture contact" without guided reflection, however, is rarely sufficient for developing intercultural competence (Bennett \& Bennett, 2004). As a result, graduate students arrive at graduate school with vastly varying levels of ability to interact effectively across cultural boundaries (Cooley, Dunn, \& Kirova, 2005).

In this article, we argue that teaching development programs with intercultural communication components provide an excellent opportunity to foster the skills that graduate students will need after graduation. First, we examine the intercultural skills that graduate students may develop during their graduate studies. Then, we demonstrate the concrete benefits of fostering intercultural competence, by reporting the results of re- 
search on the impact of two teaching development programs at a large Canadian research university. We examine how students use their newly acquired intercultural skills in their work as teaching assistants, and report on how students transfer these skills to other areas of graduate study, such as supervision and research. Finally, we examine how teaching development programs may contribute to the preparation of graduate students for the global workplace.

\section{Why Develop Intercultural Competence in Graduate School?}

In their role as students in the international environment of Canadian higher education, master's and doctoral candidates interact across cultures daily with their peers and professors. Intercultural competence enables them to manage their workload, negotiate funding, identify mentors (Dimitrov, 2009), and resolve conflicts effectively when needed (Adrian-Taylor, Noels, \& Tischler, 2007).

In their role as teaching assistants (TAs), graduate students navigate cultural differences in communication in their classroom on a daily basis because students and TAs from different cultures may have very different expectations for teacher behaviours and communication styles (Eland, 2001; Watkins \& Biggs, 2001). Cultural differences are especially common in areas such as the power distance between instructors and students, expectations for participating in class discussion, preferred ways of critiquing others' ideas, or writing and reasoning style in a particular discipline (Brown, 2008; Crabtree \& Sapp, 2004; Eland, 2001; Gorsuch, 2003; Hoekje \& Williams, 1994; McCalman, 2007). For example, interrupting a speaker and adding one's own ideas to the conversation is a sign of interest and engagement in some South American and Mediterranean cultures, whereas in a Japanese or Korean classroom, interrupting the instructor may be perceived as disrespectful (Laroche, 2003; Wieland, 1991). Interculturally competent teaching strategies allow TAs to use cultural differences as opportunities for learning and to avoid misunderstandings with their students.

Finally, when graduate students teach, they serve as role models for the undergraduate students in their class. For example, TAs may model global awareness when they teach about international or diversity-related issues. By modelling openness to different perspectives, they help their undergraduate students develop perspective taking, which is a key component of intercultural competence (Bond, Qian, \& Huang, 2003). By creating an inclusive classroom where students can share a variety of perspectives and challenge mainstream approaches to research (Ouellett, 2005), TAs can encourage cognitive flexibility and critical thinking, or they can model how to encourage contributions from ESL learners and from students who may hold a minority opinion during a debate in class (Cushner \& Mahon 2009; Harlap, 2008).

\section{What Areas of Intercultural Competence Can Be Developed in Teaching Programs?}

The teaching development programs offered at many Canadian universities provide an opportunity for graduate students to enhance their intercultural and interpersonal communication skills. In these programs, graduate students typically give short teaching presentations and receive feedback on their performance. They engage in collaborative learning with peers from a variety of cultural, disciplinary, and linguistic backgrounds. In 
teaching development programs that include intercultural communication components, graduate students may develop a form of intercultural teaching competence (Dimitrov, 2013) through these learning activities.

Intercultural teaching competence (ITC) is the ability of instructors to interact with students in a way that supports the learning of students who are linguistically and culturally different from the instructor or from each other and that is effective and appropriate in the context of teaching (Fantini, 2009). ITC includes the ability to communicate with minimal loss or distortion (Fantini, 2009), meaning that students receive and understand the messages and meaning that the instructor intends to communicate to them. It is a set of skills that allows TAs to establish meaningful relationships with students, peers, and faculty and enables TAs and their students to work together to achieve common learning goals (Fantini 2009; Spitzberg \& Chagnon, 2009). ITC enables TAs to bridge cultural and linguistic differences in the classroom as well as to communicate successfully across disciplinary cultures (Dimitrov, 2012).

The ITC concept was developed by combining existing concepts from two distinct research literatures. ITC combines elements of intercultural competence models (Chagnon, 2009; Deardorff, 2006) and work in the intercultural communication literature on interculturally competent teaching (Bennett, 2011; Deardorff, 2009) with research in the fields of educational development and educational psychology on effective teacher behaviours (Brookfield 1995; Murray, 1997), teaching assistant competencies (Shannon, Twale, \& Moore, 1998; Smith, 2001), and inclusive teaching (Ouellett, 2005).

ITC is similar to general intercultural competence in the sense that it has attitudinal components (e.g., tolerance for ambiguity, openness to difference) as well as knowledge components (e.g., knowledge of cultural differences in classroom interactions) and behavioural components (e.g., the ability to use culturally appropriate feedback strategies; Deardorff, 2006). ITC goes beyond general intercultural competence models in that it identifies specific teacher skills, behaviours, and teaching approaches that facilitate learning in the context of the culturally diverse classroom. The existing literature on interculturally competent teaching has focused primarily on social science classrooms (Deardorff, 2009) where instructors facilitate discussions about identity involving topics such as race, privilege, class, and equity (e.g., in history, sociology, or political science courses). In this article, we examine ITC across all disciplines and also explore the skills that TAs need in diverse labs, tutorials, and classrooms in engineering, science, medical sciences, and other disciplines outside the social sciences.

Based on the synthesis of the two research literatures above, the skills of an interculturally competent teacher include the ability to:

1. Model and encourage perspective taking in their classroom. For example, recognize when students approach global issues from monocultural/ethnocentric perspectives, and encourage students to consider the same issue from a variety of perspectives by asking questions and expressing a diversity of opinions in class (Bennett \& Bennett 2004; Bond, Qian, \& Huang, 2003).

2. Model and encourage non-judgemental approaches to discussing cultural, social, or other types of difference. For example, encourage students to first describe and interpret cultural differences in gender roles or health-care practices before evaluating them (Bennett, 2011; Harlap, 2008). 
3. Facilitate discussion among students with a variety of communication styles. For example, recognize differences in turn taking; manage interruptions; and perceive and comprehend high-context and low-context, as well as circular and linear contributions from students (Hall, 1986; Wieland, 1991).

4. Create an inclusive learning environment that recognizes the barriers students face in participating. For example, in some students' home cultures, women may only speak when the men are finished talking, or students only contribute when they are called upon to do so (Eland, 2001).

5. Expect and accept difference, and appreciate differences in the relationships between teachers and learners across cultures. Such differences may include: differing expectations regarding the amount of power distance between teachers and students; or differing expectations with respect to learner initiative (Cryer \& Okorocha, 1999; Dimitrov, 2009), as well as differences in students' orientation to rules and rule following (Nisbett, 2004).

6. Provide feedback across cultures in a variety of ways. Effective facilitators adjust their feedback style to the needs of learners and recognize the way feedback is offered and received in the learners' cultures or learning styles (Laroche, 2003).

7. Tailor messages to audiences with different levels of linguistic ability and limit the use of jargon and colloquialisms that may interfere with a given audience's understanding (Cushner \& Mahon, 2009).

8. Explain unspoken assumptions of one's own culture and discipline to students from different cultural backgrounds, and mentor them during their transition to Canadian academia. For example, articulate the value of academic integrity and highlight cultural differences in citation and referencing, or create assignments that take into account the discomfort that students from Confucian educational cultures experience when asked to critique the ideas of others (Watkins \& Biggs, 1999).

9. Design assessments that recognize and validate cultural differences in writing and communication styles, such as the use of inductive or deductive logic and circular rather than linear reasoning in student essays (Eland, 2001; Fox, 1994).

10. Model tolerance for ambiguity when students with a variety of learning and communication styles contribute to class discussions, and help learners deal with uncertainty. For example, rephrase circular contributions for linear learners, demonstrate patience with longer or high-context comments in class, and validate student responses (Bennett, 2011; Paige, 1993, 1996).

11. Identify risk factors for particular types of learners. Examples of risk factors are loss of face, loss of group identity, conflict avoidance, and risk of self-disclosure related to culture, religion, sexual orientation, and socio-economic background (Bennett, 2011; Paige, 1993).

12. Create opportunities for interaction among learners that allow them to learn from each other, share different perspectives, and share the wealth of cultural knowledge they bring to class (Arkoudis et al., 2013). 
13. Develop an awareness of one's own culture and cultural identity, how these are perceived by cultural others, and how they influence cross-cultural interactions-for example, the potential influence of a perceptual lens created by one's sexual orientation, race/whiteness, privileged socio-economic status, or ability to speak a dominant language (Harlap, 2008).

There is significant overlap between the best practices of reflective educators who use learner-centered teaching approaches (Brookfield, 1995; McAlpine \& Weston, 2000) and the best practices of interculturally competent teachers who model perspective taking, seek feedback, and revise their instructional approaches to meet student needs (Bennett, 2011; Deardorff, 2009; Paige, 1996). This overlap is one of the main reasons that teaching programs provide a wonderful opportunity for developing the intercultural competencies of graduate students. Teaching programs also allow graduate students to become part of a diverse community of instructors. The proportion of international students participating in teaching programs is very high (Boman, 2013), giving participants an opportunity to form lasting professional relationships with peers across cultures.

The facilitation skills that TAs acquire as part of teaching development programs are also highly transferable. Giving feedback across cultures, clarifying expectations, and being mindful about others' need to save face are skills that they can use when they conduct collaborative research, take on a leadership role, supervise junior colleagues, or present their work at international conferences.

It is important to emphasize here that teaching practices that promote interaction in diverse classrooms also improve learning for all. Thus, ITC is a developmental goal for all university teachers, not only for international TAs or domestic TAs teaching international students (Cooley, Dunn, \& Kirova, 2005). The teaching strategies that benefit ESL learners, such as providing clear outlines for class, defining key concepts, or encouraging peer learning, also benefit students with a variety of learning styles and learning disabilities, or students who are new to the discipline or new to disciplinary discourse.

\section{How Do Graduate Students Apply Their Intercultural Skills in the Class- room?}

In 2011-2013, we conducted research on the impact of two teaching development programs at a large Canadian research university (Dawson, Dimitrov, Meadows, \& Olsen, 2013). The purpose of this larger research study was to determine whether or not a TA development program enhanced with substantive intercultural communication components may help improve the teaching skills of international teaching assistants (ITAs) more than a general TA development program. For the larger project, we used a combination of qualitative and quantitative measures to compare the impact of the programs on participants' teaching self-efficacy, communication apprehension, and teaching practice (see Dawson et.al., 2013 for further information). The focus of the current article is not on comparing the two programs, but on determining the opportunities that these programs provide for the development of intercultural competence. Our research questions are:

1. What intercultural skills do graduate students learn in teaching development programs?

2. How do graduate students apply these skills in their teaching after the programs? 


\section{Programs Studied}

The graduate students who participated in the research had completed one of two programs: the Teaching Assistant Training Program or the Teaching in the Canadian Classroom program. Both programs include some instruction on cultural differences in communication styles, but to varying extents. Both programs are 20-hour, intensive TA training workshops that include video recorded microteaching sessions. During microteaching, participants receive feedback on two separate 10-minute lessons that they facilitate in a simulated classroom (i.e., graduate student peers play the roles of students/learners).

The Teaching Assistant Training Program (TATP) is a general program offered to all graduate students, although $50 \%$ of the participants tend to be international graduate students. The goal of TATP is to introduce new graduate students to teaching at the university level and help them become familiar with the basics of course design, marking strategies, facilitating class discussions, and active learning. The intercultural component in this program is a two-hour video case study on teaching in the intercultural classroom.

The Teaching in the Canadian Classroom program (TCC) is a workshop designed solely for international teaching assistants. The goal of TCC is similar to TATP, but a discussion of culture and communication in the classroom provides the framework for the course and is infused in all of its learning activities. TCC includes the same two-hour video case study as TATP; in addition, participants discuss cultural differences in communication styles, feedback styles, and expectations for teacher and student behaviour throughout the workshop.

\section{Method}

Focus group interviews were conducted four to seven months after each workshop. The research was approved by the university's Research Ethics Board. Participation in the research was voluntary, and none of the researchers were involved in direct instruction in the programs under study at the time of data collection. Participants were invited to indicate their willingness to participate in focus group interviews when they completed a survey for the larger research project (Dawson et al., 2013).

Group interviews ranged from 45 minutes to one hour and involved three to five participants, a researcher, and a research assistant. After reading the consent form and filling out a demographic questionnaire, participants answered four interview questions about (1) their motivation for enrolling in the program, (2) the most beneficial aspects of participation in the program, (3) key pieces of learning, and (3) examples of how they applied the concepts or strategies learned in the program. The interview guide included a series of probes and clarification questions to maintain consistency in questioning across groups.

\section{Participants}

The focus group interviews involved 24 participants (12 female, 12 male; mean age 26; 12 master's students, 12 doctoral students; 14 TATP, 10 TCC). The groups included four Canadian and 20 international students. For the international students, the length of time spent in Canada ranged from six months to 10 years (average one to three years). The most frequently represented cultures included Iran, China, and Pakistan, as well as several Latin American and Eastern European cultures. The four Canadian students were 
born and raised in Canada (three English speakers, one French speaker). The disciplines of participants included arts and humanities, education, engineering, health sciences, medicine, natural sciences, and social science.

\section{Data Analysis}

The interviews were audiorecorded and partially transcribed, then coded using a theme analysis approach (Miles \& Huberman, 1994). During coding, key themes related to the research questions were identified, such as concrete examples of skills learned (e.g., ability to use student engagement techniques, ability to rephrase student questions) and examples of how participants' knowledge of cultural differences influenced their interactions with students in class (e.g., they used low-context messages or withheld judgement when students used very informal communication styles). After the first round of coding, similar themes were grouped into larger categories (Strauss \& Corbin, 1990). Exact quotes representing each frequently occurring theme were then fully transcribed based on the audio recordings. To ensure participant anonymity, participants' quotes are identified only by their faculty, the degree type, and the program they attended; information concerning their home countries and departments has been removed.

\section{Results}

In the focus group interviews, the graduate students provided many examples of intercultural teaching competence in their daily interactions with their students. First, all participants demonstrated a greater awareness of their own cultural identity and the cultural assumptions they brought with them to classroom interaction. Second, they demonstrated an ability to reflect on intercultural interactions with their students and choose culturally appropriate communication strategies during challenging interpersonal situations. Finally, they not only applied intercultural competence in the classroom, but also transferred their new knowledge of intercultural communication concepts to their interactions with faculty, graduate student peers, and university staff. The results described below were equally likely to occur among Canadian and international participants. The examples of intercultural teaching competence that participants cited were clustered around three main themes

\section{(1) Expecting Difference (Maps Onto ITC Components 2, 5, 10)}

First, an important attitudinal change resulted from the programs, in that graduate students came to expect cultural and disciplinary differences in new situations and withheld judgement until they understood the intentions of those with whom they were interacting. This change was cited by both international and Canadian participants, although the examples cited by Canadian participants focused more frequently on disciplinary differences, whereas those cited by international participants focused more frequently on cultural differences.

For example, the course helped graduate students understand that there are "many different ways of doing things, not just one standard" or that "what is rude in my home culture is not rude in Canada." They talked about expecting differences in levels of participation in class discussions, depending on an undergraduate student's learning style, 
cultural background, or personality. An engineering student said that the course helped him "not to overreact to students with different communication styles," and that he "realized that he has to be cautious" in order not to be misunderstood by students. A student in social science described the key skills he learned in the course as "being mindful of student needs when teaching international students who come from different educational paradigms." Others explained that after watching their fellow graduate students from different disciplines teach during the workshop, they realized that there are differences in the expectations of students from other faculties.

It was interesting to listen to science-based TAs discuss grading and see how different it is from social science. So, this will be helpful to me in the future when I teach science students, and if they ask me about why they got a 75, I will be able to explain to them how we mark papers in social science and how it is different from science. (social science, doctoral student, TATP)

Expecting difference was a point of new learning for half of the focus group participants, while the other half arrived in the class with a basic understanding of cultural differences and decided to participate "in order not to accidentally insult students," or to "see the environment of teaching in the Canadian classroom." The key piece of learning for one participant was that the Canadian classroom is multicultural, and a diversity of views and expectations will be the norm, while another reflected on the need to "adapt [herself] to the diversity of students in the classroom, not just to Canadians."

The cognitive flexibility and tolerance for ambiguity that accompanies expectations of difference also enabled graduate students to be less afraid of making mistakes, to be more willing to ask for clarification, and to seek feedback from their students or professors to make sure that their message was received by the listeners as intended.

\section{(2) Applying Intercultural Competence in Interpersonal Interaction (Maps Onto ITC Components 5, 6, 7, 10)}

Participants applied the knowledge of cultural differences in non-verbal and verbal communication to their interpersonal interactions with students and faculty. TCC students were especially reflective about their interactions and talked about carefully choosing their communication strategies in challenging situations, such as when setting boundaries with students or responding to student concerns and grade complaints. When navigating difficult conversations, they were careful to use non-threatening, gender-sensitive, collaborative, and lower power distance language. They applied active listening skills and felt more prepared to respond to student complaints. For example, an engineering TA in TCC described meeting with students who were upset about their grades:

So one thing that helped was... the listening part, showing them that you understand the needs of the student and their perspective. And when I was explaining my perspective, I was trying to make sure that my tone is very soft.

In addition, all participants reflected on cultural differences in power distance or levels of informality before speaking with students and faculty. Others noticed cultural dif-

ferences in fairness and noted that in their home culture, professors had "favourites" in 
class, whereas in Canadian culture, treating all students equally is important, so they were careful to be fair in supporting and marking student work.

Participants also became aware of cultural differences in non-verbal communication and started to notice when their students used body language to communicate disagreement, interest, or uncertainty in class. A Canadian TA explained that after learning about the role of longer silences in encouraging reflection in some cultures, he did not feel the need to jump in to break the silence every time there was a pause in the conversation among international students in his class. An international TA said she worked on smiling more frequently in order to appear approachable and build rapport with her class. Many of the participants talked about becoming more aware of students' need for saving face.

The cultural dimension most frequently identified by participants as the key piece of learning from the course was the difference between high- and low-context cultures (Hall, 1986). Understanding differences between the responsibilities of the speaker and the listener helped graduate students realize they may under-explain or over-explain concepts. As a result, they adjusted their presentation style, worked to find out how much context/ background knowledge their listeners had, checked for understanding, and defined new terms. "I learned that Canadian culture is low-context, so I must explain everything to students," said a master's student in science. Several participants realized that they assumed a lot of background knowledge in their students and gave high-context presentations when they arrived in Canada, but after the course, they consciously revised their approach and started the semester with low-context lessons that included more details and definitions to build a shared context or knowledge base in their classes.

Before the training, I was just assuming that my students had the background knowledge, and I have come to realize that they all didn't because they are interdisciplinary. This has helped me to make my presentations more connected to common languages... it taught me how to read the audience and to realize when my students do not understand the content of the lesson. (health sciences, doctoral student, TATP)

[The difference between high- and low-context cultures] was a really great suggestion... that you can't use high-context information in every setup. If you are at a conference, as long as you are on the same page, all of you are on the same levelin fact, low-context would be an inappropriate way of speaking. But if you are in a classroom, and that classroom is new for you and you are new for the audience, then go low-context until you get the feel of the class. (medical sciences, doctoral student, TCC)

Several participants talked about becoming more reflective about the potential impact of communication styles as a result of learning about this cultural dimension. They started to notice high- and low-context approaches in presentations by faculty members in their department and noted the way the two styles sometimes caused misunderstandings. They also reflected on how they could approach these difficult situations better and use their knowledge of communication styles to prevent misunderstandings from happening. 


\section{(3) Applying Presentation Skills Across Disciplines (Maps Onto ITC Compo- nents $3,5,6,7,10$ )}

Learning about cultural differences in presentation styles (e.g., expectations for linear or circular reasoning, use of inductive or deductive logic, articulation of the thesis of a speech up front or at the end) enabled graduate students to give more effective research talks and teaching presentations and to engage their audiences more actively. They gained confidence during the microteaching sessions when they received positive feedback from peers. International graduate students worried less about their accents, partly because they realized that if their peers from around the world understood their speech in the workshop, they would be able to communicate with any audience. "The diversity of the group was helpful in realizing that the accent is not a drawback if you communicate the knowledge correctly," explained a master's student from science. "After microteaching three times, I felt very confident presenting my project in front of the department's professors. Eye contact really does wonders. I felt I was less nervous, and I was able to understand their questions after the presentation" (medical sciences, master's student, TCC). Participants emphasized the value of presenting to an interdisciplinary audience and having to define key concepts and articulate their assumptions to make their ideas accessible. They talked about slowing down their speech, repeating main points, making complex ideas simple, and using transition phrases to guide their listeners - all strategies that facilitate communication in a multicultural or multidisciplinary environment.

For the presentations in TCC, I had to pick a topic that was considered difficult in engineering and I had to teach it to non-engineers, who were in education or computer science. So, that was very interesting because in that case, you have to make sure that you teach the concept but you teach it in a way that they get it, even though they don't have the background. So, this actually helped me to present more complex things in a simple way, and that was very helpful for my engineering students, too. (engineering, master's student, TCC)

The experience of giving presentations in an interdisciplinary setting also helped graduate students learn how to read the audience and seek feedback during presentations, and it taught them the value of incorporating feedback to improve their work. After the program, they continued to apply these skills in their teaching, at conferences, and at job interviews.

\section{Discussion}

Participants in the programs under study demonstrated progress in the development of intercultural teaching competence in several ways. First, they developed an awareness and acceptance of cultural and disciplinary differences. Accepting cultural difference and recognizing the validity of different belief systems is a key stage in the development of intercultural competence (Bennett, 1993) and is identified as a fundamental cognitive shift that enables individuals to develop more advanced levels of intercultural maturity (King \& Baxter-Magolda, 2005). Understanding the limits of one's knowledge and seeking information about expectations in a new culture is another important attitudinal component of intercultural competence (Spitzberg \& Chagnon, 2009) that participants demonstrated 
in their teaching. Graduate students transferred the awareness of differences to contexts such as graduate supervision, where they asked questions to clarify their supervisors' expectations for conducting research and getting published or to avoid misunderstandings in everyday matters such as being on time for meetings.

Second, participants made significant gains in the knowledge component of ITC by demonstrating knowledge of cultural differences in communication styles, and by using intercultural communication strategies to bridge these differences. They also became more aware of the communication patterns that characterized their own culture and were able to reflect on how these patterns may influence their interactions with others.

The combination of these two areas-an attitude of openness and knowledge about their own culture as well as other cultures-allowed graduate students to approach new interactions with an informed frame of reference, also referred to in the literature as cultural empathy or a multicultural worldview (Spitzberg \& Chagnon, 2009). This informed frame of reference enabled students to choose effective and culturally appropriate communication strategies in a variety of teaching, interpersonal, and public-speaking situations (Deardorff, 2006). Communicating along the high-low context continuum effectively, for example, required tolerance for ambiguity and cognitive flexibility, as well as an understanding of this cultural dimension itself.

The competencies that participants gained in the program contributed to their success in areas of academic life beyond teaching, such as in their own course work (especially in interdisciplinary courses), and in giving conference presentations, interacting with faculty members from diverse backgrounds, and working with post-doctoral fellows from different cultures in their labs. It is important to note here that during the focus group interviews, no specific question was asked about the application of intercultural skills outside the classroom, yet in each focus group, participants volunteered many examples of how the programs improved their ability to interact across cultures in general.

\section{Conclusions}

When they enter the workplace, graduate students are often identified as potential leaders, given their training in areas such as project management and leading teams. However, to be successful, leaders in a diverse workplace specifically need to acquire intercultural skills and knowledge (Chuang, 2013). This all suggests that to be able to communicate effectively across cultures, it is essential that graduate students receive specific training in this area.

The research suggests that graduate students who have had an opportunity to reflect consciously on their intercultural skills, receive feedback on those skills, and develop a foundation of intercultural knowledge will be better prepared to take on leadership roles in diverse groups. They will be better prepared to mentor junior researchers in their labs, manage complex projects that require tolerance for ambiguity, and communicate their ideas clearly to a variety of audiences (e.g., granting bodies, community organizations, or business clients; House, Hangles, Javidan, Dorfman, \& Gupta, 2004).

The transferable skills that participants developed in teaching programs also match a number of the skills that the Canadian Association of Graduate Studies (2008) has identified as necessary for new researchers in a global society, and that the Conference Board of Canada (2013) has identified as employability and innovation skills. Specifically, par- 
ticipants in the two programs developed key skills such as "openness to uncertainty," "the ability to accept and incorporate feedback," "the ability to recognize and respect people's diversity, individual differences, and perspectives," the "ability to question and challenge the way one operates," "openness to new ideas and different ways of doing things," and the ability to "build and maintain relationships inside and outside one's organization, and with people from diverse backgrounds."

As Carr (2012) suggests, given our increasingly globalized workplace, these are skills all graduate students need to develop to be effective employees and effective leaders in their field. Furthermore, he argues that our technological communication skills have evolved to the point where the knowledge and research networks our graduate students come in contact with are likely to be spread across the globe. These students have also become increasingly globally mobile, moving from country to country as part of their education. Even within Canada, students are going to encounter a highly globalized workforce upon graduation. Statistics Canada (2008) found that the population reported over 200 different ethnic origins in the 2006 census. The 2014 Jobs Report on the Canadian labour market suggests that "immigrants now account for 22 per cent of the working-age (25 to 64 years old) Canadian population... immigrants continue to be over-represented among Canadian university degree holders, accounting for about a third of all university degree holders and 60 per cent of all engineering degree holders" (Department of Finance Canada, 2014, p. 39).

Teaching development programs enhanced with intercultural communication components therefore allow graduate students to develop a highly transferable set of interpersonal and facilitation skills that are sought by employers both in academia and in industry settings. As faculty supervisors and educational developers encourage graduate students to participate in these programs, they need to help graduate students reflect on the competencies they have gained in training programs and articulate them to potential employers after graduation.

\section{References}

Adler, N. (2008). International dimensions of organizational behavior (5th ed.). Mason, OH: Thompson South-Western.

Adrian-Taylor, S. R., Noels, K. A., \& Tischler, K. (2007). Conflict between international graduate students and faculty supervisors: Toward effective conflict prevention and management strategies. Journal of Studies in International Education, 11(1), 90-117.

Arkoudis, S., Watty, K., Baik, C., Yu, X., Borland, H., Chang, S., Lang, I., Lang, J., \& Pearce, A. (2013). Finding common ground: Enhancing interaction between domestic and international students in higher education. Teaching in Higher Education, 18(3), 222-235.

Bennett, M.J. (1993). Towards ethnocentrism: A developmental model of intercultural sensitivity. In R.M. Paige (Ed.), Education for the Intercultural Experience (pp. 21-71). Yarmouth, ME: Intercultural Press.

Bennett, J.M.(2011, February).Developing intercultural competenceforinternational education faculty and staff. Paper presented at the Association of International Education Administrators Conference, San Francisco, CA. Retrieved from http://www.intercultural. org/documents/competence_handouts.pdf 
Bennett, J. M., \& Bennett, M. J. (2004). Developing intercultural sensitivity: An integrative approach to global and domestic diversity. In D. Landis, J. M. Bennett, \& M. J. Bennett (Eds.), Handbook of intercultural training (3rd ed., pp. 147-165). Thousand Oaks, CA: SAGE.

Benninghoff, M., \& Sormani, P. (2008). Culture in interaction: Academic identities in laboratory work. In J. Välimaa \& O.H. Ylijoki (Eds.), Cultural perspectives on higher education (pp. 109-127). New York, NY: Springer.

Boman, J. (2013). Graduate student teaching development: Evaluating the effectiveness of training in relation to graduate student characteristics. Canadian Journal of Higher Education, 43(1), 100-114.

Bond, S., Qian, J., \& Huang, J. (2003). The role of faculty in internationalizing the undergraduate curriculum and classroom experience. CBIE Research, 8, 1-19.

Brookfield, S. D. (1995). Becoming a critically reflective teacher. San Francisco, CA: Jossey-Bass.

Brown, L. (2008). Language and anxiety: An ethnographic study of international postgraduate students. Evaluation and Research in Education, 21(2), 75-95.

Canadian Association of Graduate Studies. (2008). Professional skills development for graduate students. Retrieved from http://www.cags.ca/documents/publications/ working/Prof\%20Skills\%20Dev\%20for\%20Grad\%20Stud\%20\%20Final\%2008\%20 11\%2005.pdf

Carr, G. (2012, October 26). Graduate students need preparation for life outside the university. The Globe and Mail. Retrieved from http://www.theglobeandmail. com/news/national/graduate-students-need-preparation-for-life-outside-university/ article4699319/

Chuang, S. F. (2013). Essential skills for leadership effectiveness in diverse workplace development. Online Journal for Workforce Education and Development, (6)1. Retrieved from http://opensiuc.lib.siu.edu/cgi/viewcontent.cgi?article=1133\&context=ojwed

Conference Board of Canada. (2013). Innovation skills profile 2.o: The skills, attitudes, and behaviours you need to contribute to innovation in the workplace. Retrieved from http://www.conferenceboard.ca/Libraries/PUBLIC_PDFS/InnovationSkillsProfile.sflb

Cooley, M., Dunn, W., \& Kirova, A. (2005). Promoting the pursuit of intercultural competence among pre-service teachers. In J. Walrond-Patterson (Ed.), One visionmany voices: Submitted proceedings from the Cross-cultural/Anti-racism Education Conference (pp. 51-57). Edmonton, AB: Faculty of Education, University of Alberta.

Crabtree, R. D., \& Sapp, D. A. (2004). Your culture, my classroom, whose pedagogy? Negotiating effective teaching and learning in Brazil. Journal of Studies in International Education, 8(1), 105-132.

Cryer, P., \& Okorocha, E. (1999). Avoiding potential pitfalls in the supervision of NESB students. In Y. Ryan \& O. Zuber-Skerritt (Eds.), Supervising postgraduates from nonEnglish speaking backgrounds (pp. 110-118). Buckingham, UK: Open University Press. 
Cushner, K., \& Mahon, J. (2009). Developing the intercultural competence of educators and their students: Creating the blueprints. In D. Deardorff (Ed.), The SAGE handbook of intercultural competence (pp. 304-320). Thousand Oaks, CA: SAGE.

Dawson, D., Dimitrov, N., Meadows, K. N., \& Olsen, K. (2013). Bridging the gap: The impact of the "Teaching in the Canadian Classroom" program on the teaching effectiveness of international teaching assistants. Toronto, ON: Higher Education Quality Council of Ontario. Retrieved from http://www.heqco.ca/SiteCollectionDocuments/ ITAs_ENG.pdf

Deardorff, D. K. (2006). The identification and assessment of intercultural competence as a student outcome of internationalization at institutions of higher education in the United States. Journal of Studies in International Education, 1O(3), 241-266.

Deardorff, D. (2009). Exploring interculturally competent teaching in social sciences classrooms. Enhancing Learning in the Social Sciences, 2(1). Retrieved from http:// www.unc.edu/world/Vol2_1_Deardorff.pdf

Department of Finance Canada. (2014). Jobs report: The state of the Canadian labour market Retrieved from http://www.budget.gc.ca/2014/docs/jobs-emplois/pdf/ jobs-emplois-eng.pdf

Dimitrov, N. (2009). The Western guide to mentoring graduate students across cultures. London, ON: The University of Western Ontario. Retrieved from http://www. uwo.ca/tsc/resources/pdf/PG_3_MentoringAcrossCultures.pdf

Dimitrov, N. (2012). The development of disciplinary communication competence among teaching assistants: A research agenda. In G. Gorsuch (Ed.), Working theories for teaching assistant development (pp. 169-199). Stillwater, OK: New Forums Press.

Dimitrov, N. (2013, May). Teaching without borders: Assessing the intercultural competence of teaching assistants. Paper presented at the Teaching Graduate Students to Teach Conference, Vancouver, BC.

Eland, A. J. (2001). The intersection of academics and culture: The academic experience of international graduate students (Unpublished doctoral dissertation). University of Minnesota, Minneapolis.

Fantini, A. (2009). Assessing intercultural competence: Issues and tools. In D. K. Deardorff (Ed.), The SAGE handbook of intercultural competence (pp. 456-476). Thousand Oaks, CA: SAGE.

Fox, H. (1994). Cultural issues in academic writing. Urbana, IL: National Council of Teachers of English.

Gilbert, R., Balatti, J., Turner, P., \& Whitehouse, H. (2004). The generic skills debate in research higher degrees. Higher Education Research and Development, 23(3), 375388.

Gorsuch, G. J. (2003). The educational cultures of international teaching assistants and U.S. universities. TESL-EJ, 7(3), 1-17.

Green, M. (2012, January). Global citizenship: What are we talking about and why does it matter? Trends and Insights for International Education Leaders. Retrieved from: http://globalhighered.files.wordpress.com/2012/o3/ti_global_citizen.pdf 
Hall, E. T. (1986). Understanding cultural differences: French, Germans and Americans. Yarmouth, ME: Intercultural Press.

Harlap, Y. (Ed.). (2008). Road to global citizenship: An educator's toolbook. Vancouver, BC: University of British Columbia \& UNICEF. Retrieved from http://ctlt. ubc.ca/files/2011/o5/rgctoolbook.pdf

Hoekje, B., \& Williams, J. (1994). Communicative competence as a theoretical framework for ITA education. In C. G. Madden \& C. L. Myers (Eds.), Discourse and performance of international teaching assistants (pp. 11-26). Alexandria, VA: TESOL.

House, R. J., Hangles, P. J., Javidan, M., Dorfman, P. W., \& Gupta, V. (Eds.). (2004). Culture, leadership and organizations: The GLOBE study of 62 societies. Thousand Oaks, CA: SAGE.

King, P. M., \& Baxter-Magolda, M. B. (2005). A developmental model of intercultural maturity. Journal of College Student Development, 46(6), 571-592.

Knight, J., \& Madden, M. (2010). International mobility of Canadian social sciences and humanities doctoral students. Canadian Journal of Higher Education, 4O(2), 18-24.

Laroche, L. (2003). Managing cultural diversity in technical professions. New York, NY: Butterworth-Heinemann.

McAlpine, L., \& Weston, C. (2000). Reflection: Issues related to improving professors' teaching and students' learning. Instructional Science, 28, 363-385.

McCalman, C. L. (2007). Being an interculturally competent instructor in the United States: Issues of classroom dynamics and appropriateness, and recommendations for international instructors. New Directions for Teaching and Learning, 11O, 65-74.

Miles, M. B., \& Huberman, A. M. (1994). Qualitative data analysis: An expanded sourcebook (2nd ed.). Thousand Oaks, CA: SAGE.

Murray, H. G. (1997). Effective teaching behaviors in the college classroom. In R. P. Perry \& J. C. Smart (Eds.), Effective teaching in higher education: Research and practice (pp. 171-204). New York, NY: Agathon Press.

Nisbett, R. (2004). The geography of thought. New York, NY: Simon \& Schuster.

Ouellett, M. L. (2005). Teaching inclusively. Stillwater, OK: New Forums Press.

Paige, R. M. (1993). On the nature of intercultural experiences and intercultural education. In R. M. Paige (Ed.), Education for the intercultural experience (pp. 1-20). Yarmouth, ME: Intercultural Press.

Paige, R. M. (1996). Intercultural trainer competencies. In D. Landis \& R. S. Bhagat (Eds.), Handbook of intercultural training (2nd ed., pp. 148-164). Thousand Oaks, CA: SAGE.

Shannon, D. M., Twale, D. J., \& Moore, M. S. (1998). TA teaching effectiveness: The impact of training and teaching experience. Journal of Higher Education, 69, 440-466.

Smith, K. S. (2001). Pivotal events in graduate teacher preparation for a faculty career. The Journal of Graduate Teaching Assistant Development, 8(3), 97-105. 
Spitzberg, B., \& Chagnon, G. (2009). Conceptualizing intercultural competence. In D. Deardorff (Ed.), The SAGE handbook of intercultural competence (pp. 2-53). Thousand Oaks, CA: SAGE.

Statistics Canada. (2008). Canada's ethnocultural mosaic, 2006 census. Ottawa, ON: Canadian Ministry of Industry. Retrieved from http://www12.statcan.ca/censusrecensement/2006/as-sa/97-562/pdf/97-562-XIE2006001.pdf

Steers, R. M., Nardon, L., \& Sanchez-Runde, C. J. (2013). Management across cultures: Developing global competencies (2nd ed.). Cambridge, UK: Cambridge University Press.

Strauss, A., \& Corbin, J. (1990). Basics of qualitative research. Thousand Oaks, CA: SAGE.

Watkins, D. A., \& Biggs, J. B. (2001). Teaching the Chinese learner: Psychological and pedagogical perspectives. Hong Kong, PRC: Comparative Education Research Centre.

Wieland, M. (1991). Turn-taking structure as a source of misunderstanding in FrenchAmerican cross-cultural conversation. In L. F. Bouton \& Y. Kachru (Eds.). Pragmatics and language learning. Monograph Series. Vol. 2 (pp. 101-118). Urbana, IL: Division of English as an International Language, University of Illinois at Urbana-Champaign.

\section{Acknowledgments}

This research was supported in part by a grant from the Higher Education Quality Council of Ontario.

\section{Contact Information}

Nanda Dimitrov

Teaching Support Centre

The University of Western Ontario

nanda.dimitrov@uwo.ca

Nanda Dimitrov is the Associate Director of the Teaching Support Centre and an adjunct research scholar at the Centre for Research on Teaching and Learning in Higher Education at Western University. Her work as an educational developer focuses on graduate education, the preparation of future faculty, international education, and mentorship across cultures. Her most recent publications have explored the development of disciplinary communication competence among graduate students, and the impact of international teaching assistant training programs on the teaching competence of TAs.

Debra L. Dawson is the Director of the Teaching Support Centre and the Centre for Research on Teaching and Learning in Higher Education at Western University, and an adjunct research professor in the Faculty of Education. She has worked and researched in the area of educational development with graduate students and faculty for over 25 years and is currently the Chair of the Educational Developers Caucus. She also has a strong interest in enhancing student development and is the co-author of Becoming a Master Student, published by Nelson. 
Karyn C. Olsen is an educational developer at the Teaching Support Centre at Western University. Her roles include facilitating suites of instructor development programs for graduate students, post-doctoral scholars, and faculty members. She is the Assistant Editor for the Teaching Innovation Projects Journal and is actively involved in the Centre's recent research on the impact of the Instructional Skills Workshop on faculty approaches to teaching. Karyn is also a bioarchaeologist and isotopist and has published on the health and diet of rural and urban medieval Europeans, and on the origins of dedicatory burials among the ancient Maya in Belize.

Ken N. Meadows is an educational researcher with Teaching and Learning Services and a researcher with the Centre for Research on Teaching and Learning in Higher Education in the Faculty of Education at Western University. He coordinates Scholarship of Teaching and Learning initiatives for the Teaching Support Centre, supports librarians and staff in their research and program evaluation endeavours, and serves as Managing Editor for The Canadian Journal for the Scholarship of Teaching and Learning. His research focuses on positive faculty and student development, the impact of educational development programs, and teaching cultures in post-secondary institutions. 